\title{
Viagens à terra estrangeira: diplomacia e transdisciplinaridade em João Cabral e Guimarães Rosa
}

\author{
Roniere Menezes I CEFET-MG
}

Para Carlos Leite Brandão

Resumo: Neste trabalho, propomo-nos a refletir a respeito do conceito de diplomacia como alegoria do trabalho artístico-intelectual e do saber transdisciplinar, tomando como exemplo passagens da vida e da obra de João Cabral de Melo Neto e João Guimarães Rosa.

Palavras-chave: Diplomacia, transdisciplinaridade e literatura.

poeta João Cabral de Melo Neto e o escritor João Guimarães Rosa apresentam em comum o fato de terem sido diplomatas. Mais do que uma coincidência biográfica, a atividade diplomática - vista como aproximação com a exterioridade $^{1}$ de um sistema, abertura para o jogo de diferenças existentes na

1. Giorgio Agamben assinala que a noção de "exterior" é expressa, em diversas línguas europeias, "por uma palavra que significa 'à porta". O fora não é um outro espaço que eliminaria o espaço interior. É o acesso, a experiência do limite, sua imagem é a soleira. Cf. AGAmBEn. $A$ comunidade que vem, p. 54. 
vida social, cultural e política - será tomado aqui como um conceito que permite articular a leitura dos dois autores. A diplomacia será focalizada como formação discursiva, uma política da escritura que se faz como ato intelectual. ${ }^{2}$

A escrita diplomática é marcada pelo aspecto protocolar e circula em ambientes oficiais. As negociações políticas com outros territórios, os conflitos de fronteiras, os acordos de paz, objetos do campo diplomático, muitas vezes aparecem traduzidos pelo campo artístico e reconfigurados no artefato artístico-literário. Em muitos dos textos de Cabral e Rosa, a escrita diplomática é tangenciada pela escritura: discurso de caráter artístico-literário que traz à tona questões relacionadas à reflexão político-social, voltada prioritariamente para questões éticas. A escritura torna-se, neste ensaio, modo operatório encontrado pelos autores para articular ideias em que o político e o estético não se separam. Pode, portanto, surgir em diversos espaços discursivos, na prosa, na poesia, em cartas, mas também em documentos oficiais de embaixadas.

Cabral e Rosa atuam, com sua escritura, no lugar da sutileza, da perspicácia, nessa fronteira intercultural onde deslizam e se agenciam diversos saberes, formulações artísticas e posicionamentos políticos. No itinerário dos escritores-diplomatas, surgem ressonâncias, aproximações, traduções entre as produções culturais de várias partes do mundo. Ao transitarem por diversas margens, os autores apresentam-se imbuídos do fazer artístico e da especificidade ética de diferentes povos e culturas. Notamos a existência de articulações entre o canto "a palo seco" espanhol e o desafio nordestino em Cabral e entre o pensamento oriental e o comportamento ascético mineiro, em Rosa. A tarefa da, aqui chamada, escritura diplomática evidencia-se, sobretudo, na obra dos autores, pela utilização sábia do afeto em relação ao outro, pelo reconhecimento do exterior em relação a lugares estabelecidos. Desse modo, questionam-se as fronteiras e divisões, presentes não apenas nas macroestruturas sociais, mas também nos micropoderes estabelecidos cotidianamente.

O trabalho diplomático, as relações com o outro, a tentativa de criar acordos - que ao mesmo tempo aproximem os discursos e marquem suas diferentes intenções - refletem-se, como ressaltamos, na criação artístico-intelectual dos escritores em estudo.

Os diplomatas Cabral e Rosa tiveram a oportunidade, em suas funções consulares, de oferecer um rosto humano e sensível à instância política. Os

2. Cf. Deleuze; PARnET. Diálogos, p. 57. 
escritores-diplomatas articulam, pelas margens dos mecanismos oficiais de poder, às vezes em países distantes, encontros inusitados entre proposições artísticas e intelectuais. Dessa forma, contribuem para a construção de novas modelagens artístico-culturais.

Os autores, além do saber escolar de fundo iluminista, desenvolveram o pensamento da estrangeiridade, a saída do centramento cartesiano e a abertura para outros modos de saber e de expressão. Ao mesmo tempo que atuam no campo burocrático ou literário, buscam a convivência com a diversidade social, estética e cultural, tanto estrangeira quanto nativa, tanto subjetiva quanto concreta, relacionada à grande arte ou à tradição popular.

\section{Descompassos cabralinos}

Em entrevista a José Castello, Cabral comenta a influência da diplomacia, dos diversos espaços em que viveu, no ofício poético. O acaso entremeia-se nas linhas do enredo. Para Cabral, se o seu roteiro como diplomata tivesse sido outro, suas influências também poderiam ser diferentes. À pergunta sobre a demarcação da rede de influências que formou sua poesia, responde:

- É, posso dizer quais foram as leituras que me marcaram. Meu primeiro posto foi na Espanha. Eu, na Espanha, procurei ler minuciosamente os primeiros autores épicos espanhóis. Essa poesia primitiva espanhola me impressionou muito. Fui marcado por ela. Depois, eu me mudei para Londres. Aí descobri a poesia inglesa. Porque, quando eu estava aqui no Brasil a gente tinha - e tem - a tendência de abordar a poesia inglesa, em geral, pelos românticos. Os românticos tiveram, todos, uma vida muito interessante, então somos atraídos por isso, pela vida deles. Lord Byron, Percy Shelley, John Keats. Agora, eu lia esse pessoal e eles não me interessavam. Quando eu fui para Londres, então, eu pude ler a poesia metafísica inglesa que eu não conhecia e isso foi uma coisa que me marcou muito. John Donne, George Herbert, Andrew Marvell, poetas que aqui no Brasil são desconhecidos. Até ali, Byron, Shelley, Keats me impediam de entrar na literatura inglesa. Foi com a poesia metafísica que a literatura inglesa começou a me interessar. Agora você pode, só por isso, falar em influência, não sei. ${ }^{3}$

3. Castello. João Cabral de Melo Neto: o homem sem alma \& Diário de tudo, p. 259-260. 
O pensamento é fruto de acasos, de encontros inesperados. Forças desconhecidas entram em cena, às vezes, demonstrando uma violência pragmática e conceitual que abala nossas certezas e amplia nossas percepções. No período em que morou em Barcelona, entre 1947 e 1950, seus primeiros anos na Espanha, Cabral estabeleceu amizade com alguns dos mais importantes nomes da intelectualidade espanhola, entre eles, Joan Miró, Joan Brossa, Jorge Guillén, Carles Ribas e Antoni Tàpies. As relações, os "agenciamentos" estabelecidos com essas pessoas foram fundamentais não apenas para transformar a visão de arte e de poesia de Cabral, como também para que fosse redimensionada a percepção dos amigos sobre o objeto artístico. Esse fato é demonstrado em cartas e entrevistas de alguns dos interlocutores espanhóis do poeta brasileiro. A ocorrência e a força dos possíveis encontros são fundamentais para o surgimento de um pensamento que se desloca da interioridade para os espaços da superfície, articulados por uma rede de entrelaçamentos não dicotômicos.

Em "Joan Miró", ensaio sobre o discurso pictórico do artista catalão, realizado em 1949, Cabral afirma que o espanhol empregava, em seus trabalhos, o adjetivo vivo. Este traria à obra do pintor algo "oposto à sensação de harmônico ou de equilibrado". ${ }^{4}$ O vivo sai desse lugar de estabilidade, busca o seu fora. Importa, na expressão artística, segundo Cabral, a capacidade de lutar contra os hábitos acomodados e quebrar a densa camada de sensibilidade, já endurecida pela rotina. A obra de Miró revela a luta contra a atenção estática, contra o hábito e contra a memória mecanizada. Visa a elaborar mecanismos de lucidez pela utilização de um estado constante de julgamento.

Além do contato com grandes nomes da literatura e da pintura, o trabalho diplomático permitiu a Cabral a descoberta de novas formas de modernidade, dentro da própria Europa. Na Espanha, presencia, nos tablados de bares e cabarés, shows de dança e música flamencas. A forte influência da cultura espanhola em Cabral, fruto de longos anos de trabalho naquele país, permite-nos notar a presença do "sotaque" popular da Espanha na obra do brasileiro.

O conhecimento dos trâmites burocráticos oficiais em conjunção com a vivência em múltiplos territórios, onde assiste a manifestações políticas cotidianas, expressões artísticas e culturais de diversos povos, confere ao escritor diplomata um lugar diferencial entre os intelectuais.

4. MELO NETO. Obra completa, p. 718. 
Rosa não destaca a temática da experiência estrangeira em suas obras, como é o caso de Cabral. Este viveu mais tempo no exterior, principalmente na Espanha. Observamos, porém, que a relação entre os processos de arte e pensamento brasileiros e estrangeiros instaura-se, na obra dos autores, de modo marcante na própria estrutura textual. As experiências e as leituras dos autores, relacionadas, por exemplo, à Espanha e à Alemanha, afetam tanto as reformulações temáticas como as articulações linguísticas.

Os períodos vividos no exterior apresentam diversas e ricas vivências aos diplomatas, e mesmo as experiências negativas fornecem elementos a serem reconfigurados futuramente pela escritura. Em Morte e vida severina, Cabral retoma, por exemplo, uma história permeada por humor negro ocorrida na Espanha, em uma cidade chamada Soria. Relata o poeta, em entrevista:

Soria estava caída nas mãos de Franco. Então pegaram um dos comunistas inimigos de Franco, Soria é a cidade mais fria da Espanha, e levaram ele para ser fuzilado a alguns quilômetros da cidade. No meio do caminho, o homem, tremendo de frio, disse: "Que frio hace em Soria." Aí os soldados que iam fuzila-lo protestaram: "O que você está reclamando, você não vai fazer a viagem de volta."

A narrativa reaparece traduzida, em outro contexto, na obra cabralina: "Mais sorte tem o defunto,/ irmãos das almas,/ pois já não fará na volta/ a caminhada.", Quando Cabral vai viver em Marselha, na França, sente-se bastante contrariado. Ao contrário de Sevilha, cidade solar e arejada, onde Cabral trabalhou durante muitos anos, Marselha parece-lhe sombria, fechada, cheirando a antiquário. ${ }^{7}$ Em carta escrita no dia 1ํㅡㄹ de dezembro de 1958 ao escritor mineiro Murilo Rubião que viveu de 1956 a 1960 como adido cultural do Brasil na Espanha -, Cabral observa:

Não posso reclamar do fato de ver-me em Marselha porque afinal de contas pedi para ir para lá. Mas Marselha depois de Sevilha é o diabo. A única

5. MELO NETO. Conversas com o poeta João Cabral de Melo Neto, p. 93.

6. MELO NETO. Obra completa, p. 175.

7. MELO NETO. Carta a Murilo Rubião. Marselha, 1. XII.958. Arquivo Murilo Rubião. Acervo de Escritores Mineiros da UFMG. 
vantagem que vejo é que aqui me impregnarei de toda a atmosfera que detesto na Europa - mofo, umidade, sujo - e que pretendo satirizar um dia. ${ }^{8}$

Em outra carta, escrita em Marselha no dia 6 de dezembro de 1958, o poeta reporta-se ao amigo comentando a falta de trabalho no posto diplomático e como esse fato leva-o ao contato com a literatura:

Depois da chegada da família, espero que minha vida entre nos eixos. O chato é que não se confirmou a esperança que eu tinha de encontrar muito trabalho no consulado. Há ainda menos aqui, do que em Sevilha. Assim, ficarei entregue a mim mesmo, o que é péssimo. Porque para dar forma a essa disponibilidade mergulharei fundo na literatura; e a literatura para mim é uma coisa tão esgotante, radical, consumidora, que breve estarei em novas crises de desespero.?

Em Marselha, além de ver-se impossibilitado de realizar os passeios pelas ruas sem automóveis, como costumava fazer ao entardecer de Sevilha, o poeta não encontra serviço no consulado. De forma ambígua, o almejado tempo ocioso torna-se indesejado, pois entregar-se à literatura revela-se um gesto autoconsumidor, autodevorador, um trabalho exaustivo. A energia vital, ao ser gasta em excesso, transforma-se em criação artística. A dificuldade de lidar com o lento fluir do tempo lança o poeta ao cuidadoso ofício poético. O trabalho realizado, no entanto, não esconde a permanente sensação de vazio, propiciando inquietudes e crises relacionadas ao antigo e sempre presente quadro depressivo.

\section{Trincheiras rosianas}

A proposição de uma perspectiva questionadora dos cânones disciplinares, como aparece no ensaio de Cabral sobre Miró, é comum na produção rosiana. No quarto e último prefácio do livro Tutaméia, ${ }^{10}$ intitulado "Sobre a escova

8. MELO NETO. Carta a Murilo Rubião. Marselha, 1. XII.958. Arquivo Murilo Rubião. Acervo de Escritores Mineiros da UFMG.

9. MELO NETO. Carta a Murilo Rubião. Marselha, 6. XII.958. Arquivo Murilo Rubião. Acervo de Escritores Mineiros da UFMG.

10. ROSA. Tutaméia: terceiras estórias, p. 156. 
e a dúvida", Guimarães Rosa aborda a questão da rotina impensada que envolve a vida humana. O escritor debruça-se sobre o fato de, em sua infância, mandarem-no escovar de jejum os dentes assim que acordasse: "Eu fazia e obedecia." Mas uma luz lhe brotara do absurdo: "De manhã, razoável não seria primeiro bochechar com água ou algo, para abolir o amargo da boca, o mingau-das-almas? E escovar, então, só depois do café com pão, renovador de detritos?" Desde o momento que lhe surgira essa dúvida passara a efetuar o asseio desse outro modo.

O pequeno texto pode funcionar para pensarmos sobre a relação entre o escritor e a desconstrução dos lugares-comuns. As reflexões, as intuições, as pesquisas, as elaborações filosóficas e intelectuais feitas a partir da construção literária têm como forte função deslocar os territórios em que dormem os homens, acomodados ou acreditando não haver outro modo de ação, outras verdades.

Em 1952, o escritor mineiro é convidado a fazer parte da equipe que prepararia o Concurso de Provas do Instituto Rio Branco. O trabalho realizado pelo diplomata refere-se ao exame de Cultura Geral e demonstra o seu interesse por conhecimentos não apenas acadêmicos e formais. Rosa valoriza modos de saber que não são aprendidos apenas em livros ou em bancos escolares, mas os "pragmaticamente" utilizáveis. Tais conhecimentos seriam gratuitos e demonstrariam a curiosidade e a consciência humanística do candidato, fatores que contribuiriam para a formação de sua personalidade. O escritor condena, no texto, a indução do concurso a leituras apressadas, que produziriam uma espécie de "memorização artificial". 11

Ao contrário da tradicional distinção entre o saber escolar - disciplinar, científico, aprendido com o esforço da razão - e a chamada sabedoria, menos valorizada pelos padrões acadêmicos, aprendida nas ruas, nos encontros, nas surpresas do cotidiano, Rosa considera fundamental a interseção entre os dois conhecimentos. Elementos da produção literária direcionam o modo de pensar e de agir do escritor, em seu posicionamento sobre o que considera primordial para a formação do caráter do diplomata ou do cidadão comum. ${ }^{12}$

A contemplação, o ócio, as formas de saber não canônicas que permitem o surgimento de uma competência para resolver certa situação inusitada fazem parte da lógica rosiana. No discurso de posse na Academia Brasileira de

11. ARAÚJO. Guimarães Rosa: diplomata, p. 29.

12. ROSA. Discurso de posse de JGR na ABL. Arquivo IEB-USP, caixa 22. 
Letras, afirma: "Desde cedo, apenas, também eu aprendi que o sábio fia-se menos da solércia e ciência humanas que das operações do Tao." ${ }^{13}$ Em Rosa, a cultura ocidental liga-se, por exemplo, ao zen-budismo oriental, tendo como mediador o pensamento sertanejo mineiro. ${ }^{14}$

No "diário alemão", ${ }^{15}$ escrito por Rosa durante os anos em que viveu na Alemanha nazista, existem relatos preciosos. O contato, na Alemanha, com textos de autores alemães, certamente enriqueciam, assim como pensa Cabral, a vivência na terra distante. No dia 25 de março de 1940, anota Rosa em seu diário: "Almocei em casa do Cônsul Geral - empada de galinha e 'pudim-de-veludo.' / Às 7 horas, na Sttatliches Schauspielhaus ${ }^{16}$ fui ver o FAUST.../ Um acontecimento!... Maravilha!.../ Heil Goethe!... / O dia foi bonito. E, ao sairmos do teatro, fazia luar." Em nota sobre a passagem, para futura edição crítica desse diário rosiano organizada pelos professores Eneida Maria de Souza, Reinaldo Marques e Georg Otte, podemos ler: "Rosa faz um jogo com a saudação nazista, substituindo o Heil Hitler! pelo Heil Goethe?'. É preciso notar, nesse sentido, o deslocamento operado pelo escritor, entre o espaço político e o cultural. Para os organizadores da futura edição do "diário alemão", esse fato revela a admiração de Rosa não por Hitler, mas por Goethe. Lembram ainda a apropriação de Fausto, de Goethe, na cena do pacto entre Riobaldo e o Diabo, em Grande sertão: veredas.

Nas anotações referentes ao dia 12 de março de 1941, Rosa escreve em seu diário a respeito de sua percepção noturna da guerra. Iniciando às 11 horas e 5 minutos, segue pontuando, com intervalos de 10 a 5 minutos, até 1 hora da manhã. Revela, como soldado em trincheira, o horror de estar entre fogo cruzado. O tempo não passa, o sono impossível transforma-se em vigília. A fina observação

13. ROSA. Discurso de posse de JGR na ABL. Arquivo IEB-USP, caixa 22.

14. No conto "Orientação", de Tutaméia, Rosa conta a história de "Yao Tsing-Lao - facilitado para Joaquim. Quim, pois." Yao-Tsing vira Joaquim e naturaliza-se Quim. Era "sério sorrisoteiro". Vivia no sertão mineiro. A descrição do chinês demonstra a tentativa de capturar outras faces e outros pensamentos, "exteriores", "de banda", perdidos nas paisagens sertanejas. ROSA. Tutaméia: terceiras estórias, p. 108.

15. Cf. ROSA. "Diário alemão". Fundo Henriqueta Lisboa. Acervo de Escritores Mineiros da UFMG. Os professores e pesquisadores da FALE/ UFMG Reinaldo Marques, Eneida Maria de Souza e Georg Otte estão organizando edição comentada do diário de Rosa, mas cuja publicação não foi ainda autorizada pela família.

16. Teatro do Estado. 
e a minúcia nos detalhes parecem querer fazer dissipar-se a angústia a que o escritor fora atirado em terras distantes. Na infindável noite, o diplomata busca a calma por meio de um testemunho que expressa, ao mesmo tempo, envolvimento da vida particular no conflito, crônica arguta a respeito da realidade externa e imaginação estética. As letras, às vezes trêmulas sobre o papel, mostram-se como únicas companheiras, frágeis veículos de libertação. Tanto Cabral em Marselha, como Rosa em Hamburgo, vivem a desterritorialização, a perda da certeza. Eles fazem da insegurança, diante da ordem estrangeira, possibilidade de criação de linhas de fuga pelo viés literário. O enfrentamento das fragilidades humanas em terras inóspitas liga-se intimamente à formulação artística. Nesse sentido, o trabalho estético recobre-se de força política restauradora, pois relaciona-se à vontade de transformação individual e coletiva. ${ }^{17}$

Além desses episódios, vale lembrar que em ofícios enviados, por Rosa, do consulado de Hamburgo ao Itamaraty, no Rio de Janeiro, o escritor relata o contato com homens destituídos das mínimas condições de cidadania. O "ser qualquer", personagem constante da literatura rosiana, aparece nas ruas da Alemanha em guerra, interferindo no modo de o escritor-diplomata pensar a roda do mundo e remodelar sua obra.

Em 1942, vindo da Alemanha e após breve passagem pelo Brasil, Rosa segue para a capital da Colômbia, Bogotá, onde permanece até 1944. Em "Páramo", conto publicado no livro Estas estórias, ${ }^{18}$ o narrador criado pelo diplomata escreve sobre um homem ainda jovem que fora parar em um lugar inóspito. A "ilha deserta" a que chega o escritor permite o contato íntimo consigo mesmo, possibilita o rompimento das certezas pessoais. O enfrentamento de adversidades, a desterritorialização e a posterior reterritorialização lembram que o sentido só pode existir em constante movimento e deslocamento. O sentido surge como resultado de momentos de "exceção e exílio", conforme aponta Raul Antelo. ${ }^{19}$ Ele irrompe da exterioridade de um signo, de um discurso, em relação com a

17. Experiências vividas pelo escritor no conflito podem ter contribuído para a construção de cenas antológicas da literatura rosiana, como a passagem de Grande sertão: veredas, em que o bando de Riobaldo e Diadorim é acuado dentro de uma casa de fazenda, recebendo tiros por todos os lados do bando rival. A tradução de sensações para espaços distintos é marca da escritura dos diplomatas.

18. ROSA. Estas estórias, p. 219-244.

19. Cf. ANTElO. Sentido, paisagem, espaçamento, p. 18-23. 
exterioridade de outros signos, outros discursos, e não da interioridade de algum

sistema. ${ }^{20}$ Rosa, nesse conto sobre as incertezas de um intelectual nas alturas dos Andes, acaba por reforçar a importância do enfrentamento de um lugar indefinido para que novas construções possam surgir. ${ }^{21}$

Gilles Deleuze assinala que o pensamento faz-se fora de qualquer espécie de garantia. A característica do novo seria produzir no pensamento forças que não fazem parte da "recognição". O desenvolvimento do pensamento capaz de produzir a novidade passa, para o filósofo, pelo contato com uma zona limítrofe, uma exterioridade em relação à certeza do sujeito pensante, já constituído. O devir resulta do rompimento de fronteiras entre mundos diversos, bem como da abertura para potências de um modelo lógico desconhecido. Esse modelo apresentar-se-ia em terras incógnitas, nunca totalmente reconhecidas. ${ }^{22}$

\section{Outras paisagens}

A busca de um fora da linguagem habitual e intimista é comum aos autores. Percorre os livros e demais produções de Cabral e Rosa a intenção de questionar princípios científicos, comportamentais e estéticos arraigados na ideia de hierarquia ou de convenção social. A racionalidade cabralina mostra-se questionadora dos dispositivos que enquadram e limitam o homem. Os autores, munidos de ferramentas do saber transdisciplinar, vasculham outras instâncias, percorrem outros mapas além do visível. Os diplomatas conhecem bem o quanto há de construção linguística, de técnica retórica, de jogos de poder em cada trecho de um argumento pronunciado. A atenção, o cuidado com as minúcias da linguagem, as estratégias de convencimento, o preparo intelectual, o controle para que aspectos sentimentais ou irrefletidos não interfiram nas negociações revelam aspectos da vigília, da "prudência" diplomática presentes na produção artística.

Com sua política da escritura, os autores questionam a concepção torta e preconceituosa que, valorizando o aspecto pragmático da modernidade, vê o artístico, o literário, a imaginação criadora como sinais de pobreza e de descrédito, de falta de reflexão séria e cuidadosa. Como se a razão e a imaginação não fossem as molas mestras tanto do discurso da ciência quanto do discurso da arte. Segundo

20. Cf. FOUCAULT. Arqueologia do saber.

21. Cf. ROSA. Estas estórias, p. 219.

22. Cf. DELEUZE. Diferença e repetição. 
essa concepção, a construção artística beberia apenas na fonte do prazer superficial. O projeto da obra, a pesquisa empreendida, as regras textuais, a técnica artística, a perspectiva política, a análise do tecido social propiciada por argumentos e alegorias, a sensibilidade aliada à consistência crítica são escamoteados.

A transdisciplinaridade permite erigir espaços de estrangeiridade em relação aos pensamentos mais íntimos, às certezas mais arraigadas. Rompe-se com o pensamento estanque, dualista. Nesse processo, é importante aprender a olhar com as lentes do outro, a sentir um pouco da insegurança que as terras desconhecidas proporcionam. A experiência da terra estrangeira provoca no viajante o desenvolvimento de percepções aguçadas, o interesse pelo novo. Reconhecer as incompletudes e as limitações dos próprios posicionamentos são meios de operar com um pensamento mais aberto, de ser tolerante em relação a diversos modos de existência.

O texto literário não funciona somente para ilustrar um raciocínio teórico, pelo contrário, suas imagens devem ser vistas como conceitos que produzem uma rede teórica de amplo alcance e que aproximam o fazer artístico da teoria crítica. Dividindo espaço com outras perspectivas científicas e teóricas, a literatura mostra-se capaz de produzir deslocamentos na percepção e na reflexão, desvelar paisagens ideológicas e criar possibilidades para novas formas de posicionamento estético e político.

Ao contrário da diplomacia oficial, vinculada a regras e dogmas, a "diplomacia literária" apresenta, como força maior, o questionamento social. O objetivo não é fechar acordos definitivos, mas revelar novos olhares políticos para o mundo. Novos modos de lidar com o conhecimento interferem no diagrama político. É bom ressaltar que a formação "iluminista" e a pesquisa enciclopédica empreendida por Rosa na confecção de seus livros aliam-se ao contato com vaqueiros, com raizeiros, a leituras literárias em várias línguas, a pesquisas em dicionários, às cartas do pai descrevendo tipos, costumes, cenas, expressões coloquiais e vestimentas do interior mineiro.

Com o passar dos anos e a maturação sempre maior da percepção política e estética, Cabral, talvez desconfiando da razão como forma definidora de luta com as palavras, possibilita uma maior entrada do "descontrole" em sua produção literária. As memórias infantis do escritor aparecem de forma mais solta em $A$ escola das facas, livro publicado em 1979. A novidade surge no modo de apresentar a criança em íntima relação com o ambiente social nordestino. A exploração de elementos autobiográficos, apesar de rara, não é novidade em Cabral; nesse livro, porém, pela força e reiteração dos motivos, ela abre portas para novas interpretações 
de sua obra. ${ }^{23}$ O livro resgata fragmentos da experiência do menino João com pessoas simples do engenho. ${ }^{24}$

\section{Poéticas de fronteiras}

A modernidade hegemônica afastou domínios do saber, enrijeceu campos disciplinares e fortaleceu áreas ligadas ao pensamento pragmático, científico, que investem na divisão, na fragmentação dos saberes e na especialização. Buscou-se, dessa forma, o desenvolvimento mais sistemático das pesquisas e a descoberta de uma suposta verdade. As áreas do saber ligadas à imaginação, ao pensamento não aplicado - mais aberto ao diálogo com outras disciplinas -, foram relegadas a segundo plano.

Atualmente, o questionamento dos alicerces da razão moderna pode ser demonstrado a partir das preocupações de algumas áreas em dialogar com outros campos do conhecimento. Há a constatação de que é necessário sair da interioridade e caminhar em direção a outras formas de pensamento, para se obter conhecimento mais amplo do objeto de estudo. O conceito de diplomacia pode contribuir para o debate transdisciplinar, a partir do momento em que esta é entendida como a busca do diálogo com uma exterioridade em relação ao sistema instituído. Nesse sentido, a diplomacia ofereceria à escritura um pensamento que se apresenta não pela capacidade de ver o outro a partir de princípios e regras consolidadas, mas pela capacidade de ser olhado por esse outro, de deixá-lo invadir o discurso e ressignificar a área de atuação, o pensamento, a sensibilidade e a ação. ${ }^{25}$ O fortalecimento vem da "estratégia de enfraquecimento" a ser utilizada durante o diálogo.

Pelo fato de vivermos em um mundo dividido entre a inteligência tecnocrática racionalista e a inteligência autocentrada, voltada para princípios

23. No livro Agrestes, de 1985, Cabral retoma, entre outros temas, a construção de poemas relacionados à memória infantil. Cf. MELO NETO. Obra completa, p. 529.

24. No livro Serial, de 1961, nota-se também a presença, na construção da série literária, de personagens habitantes da infância do menino Cabral, resgatadas pela memória inventiva.

25. Cf. DERRIDA. O animal que logo sou. (a seguir), p. 28. 
"invioláveis" e "seguros" do "eu", seria preciso aprender a desenvolver o pensamento da exterioridade, ou da complexidade, conforme pensa Edgar Morin. ${ }^{26}$

A valorização dos conhecimentos não científicos na obra dos autores em foco não significa o descrédito das formas de saberes científicos ou pautados pela racionalidade, mas, antes, sua utilização de forma contra-hegemônica. $O$ pensamento fronteiriço não atribui o mesmo crédito a todos os conhecimentos e formulações artísticas, mas busca desconstruir os discursos que desconsideram, de início, tudo aquilo que não se aplique ao "cânone epistemológico da ciência moderna”. ${ }^{27}$ Não se propõe a banalização do conhecimento, sua simplificação. Busca-se, ao contrário, um movimento em direção ao exterior que motivaria, além do desenvolvimento científico, o desenvolvimento da imaginação e da crítica. Os discursos de poder perderiam os donos e seriam desconfigurados na criação de novos modos de se trabalhar com o conhecimento. O rompimento das fronteiras entre as disciplinas ampliaria o poder crítico, a partir da interpenetração "de discursos, de metodologias, de experiências diversas". ${ }^{28}$ Com a transdisciplinaridade, o pensamento intuitivo e criador do poeta seria rearticulado com instrumentais analíticos relacionados à ciência e à tecnologia. A chamada ordem da descoberta encontrar-se-ia com ferramentas que buscam a justificação do conhecimento. Desse modo, seria possível ultrapassar operações metodológicas tradicionais que enxergam na literatura, na psicologia e na filosofia apenas características aleatórias, sem validade epistêmica, conferindo à matemática, à lógica, o verdadeiro lugar do conhecimento.

As poéticas de fronteiras nascem da interação de diferentes pontos de vista. Não contrapõem o saber moldado pela razão, diurno, à sabedoria tecida pela arte e pela imaginação, noturna. Cabral contraria, com sua poesia, o diálogo mais livre entre razão, sensação, intuição e sabedoria popular, marca distintiva do discurso rosiano. No entanto, a obra cabralina não pode ser avaliada sem a comparação com outras linguagens. No trabalho dos escritores-diplomatas, palavras, conceitos, imagens, sons - transitando pelo universo da literatura, da arquitetura, das artes plásticas e da música, pelos campos da cultura e da política - interpenetram-se e sugerem novas abordagens teóricas, novas estruturas de sentimento. O lugar conceitual

26. MORIN. Educação e complexidade: os sete saberes e outros ensaios, p. 47.

27. Cf. SANTOS. Para um novo senso comum: a ciência, o direito e a política na transição paradigmática, p. 109.

28. Cf. DOMINGUES. Conhecimento e transdisciplinaridade II, p. 36-37. 
proporcionado pela interação entre o discurso diplomático e o artístico-literário mostra que, se o diplomata às vezes mente, ou esconde conhecimentos visando a acordos mais profícuos, o poeta, o escritor, o artista inventam mentiras que nos possibilitam enxergar verdades maiores que as certezas aparentes.

A imagem do intelectual diplomata, presente não nos tratados oficiais, mas na "diplomacia menor" - vislumbrada na confecção de obras artísticas e literárias, nos discursos e ensaios -, revela uma performance, enquanto funcionamento simbólico, de um modelo para o trabalho com o pensamento crítico. A imaginação estética mesclar-se-ia a outras formas de pesquisas mais sistemáticas do ponto de vista da ciência, preservando-se o rigor dos campos teóricos, buscando-se, portanto, uma compreensão mais abrangente e mais dinâmica do mundo. A maior consciência a respeito do caráter representativo do discurso, da distância entre as palavras e as coisas, traz a desconfiança em relação à pretensão de verdade absoluta.

\section{O conceito de "diplomacia" como operador discursivo}

O sociólogo francês Bruno Latour, ao discorrer sobre a ecologia política, chama à cena contemporânea a imagem do antigo corpo de trabalho do diplomata. A função deste, visto agora como cidadão crítico contemporâneo, consistiria em acompanhar, esclarecer e atuar como intérprete das questões político-sociais. ${ }^{29}$

Para Latour, o diplomata ligado à ecologia política não trabalha no âmbito das referências comuns, e sim no das divergências. O objetivo da diplomacia consistiria em aproximar-se da ideia de um mundo mais próximo do comum. Esse profissional, conceitualizado pelo sociólogo, arrisca-se, corre perigo para tentar construir o mundo comum. Nunca estará conformado com as decisões incomensuráveis que levam às guerras mundiais ou cotidianas, mostra-se sempre atento às formulações mais simples e menos pretensiosas, pois elas podem conter a fagulha do acordo que se busca.

A incerteza funciona como "embaraços de fala" diante de dados inusitados que ocorrem, por exemplo, nas crises de desemprego ou ecológicas. Passa a ser vista como "ingrediente inevitável" de uma nova proposição político-discursiva. Em vez de esperar a voz taxativa e inflexível da ciência objetiva, os "embaraços de fala"

29. Cf. LATOUR. Políticas da natureza: como fazer ciência na democracia, p. 344 . 
incorporam, no diálogo, o signo "discutível". Este corrói as proposições "régias" que pretendem impor o "indiscutível". Abre-se para a convivência entre a objetividade científica e as múltiplas controvérsias, gerando novos e inconclusos entendimentos.

A natureza da indecisão representa um dos fatores mais importantes para que se possa transformar a posição dos envolvidos em um processo discursivo. O pensamento oposto é um dado concreto a respeito das formas diversas de se entender a realidade. Ao incluir o discurso alheio como parte do próprio discurso, o interlocutor age "diplomaticamente", amplia os modos de percepção e de explicação do mundo. 30

A ciência moderna exige do sujeito a "neutralidade" e a "consciência objetiva". Busca-se evitar a "contaminação" do pesquisador em relação aos dados da realidade que analisa. A imparcialidade e o distanciamento promoveriam um entendimento maior e mais profundo do objeto de estudo. Notamos, no discurso literário e não literário dos três escritores, outro modo de lidar com os artefatos e com a realidade.

Cabral pretende manter-se distanciado da força lírica e construiu para si uma imagem de poeta frio e racional. Isso aproximaria sua obra do discurso científico, porém, a distância entre os objetivos finais da poesia e da ciência, como sabemos, é quilométrica. O controle da ciência visa à resposta exata, à proposição definitiva. Mesmo rompendo com a visão tradicional de poesia, no Brasil, o controle cabralino é meio para se alcançar o descontrole. Os mecanismos de concentração e de objetivação almejam elidir a dispersão tanto do poeta quanto do leitor.

Ao procurar estabelecer o "controle da explosão", para que a flor na mão do toureiro não se perfume nem poetize o poema - como é explicitado em "Alguns toureiros", de Paisagens com figuras ${ }^{31}$-, o jogo imagético e formal de Cabral visa, de fato, a emocionar o leitor. A mão do toureiro que segura a flor é "serena e contida", "certa, pouca e extrema". A posição de combate poético faz-se na fronteira, como a presença do toureiro espanhol que se expõe a partir da

30. Cf. HISSA. A mobilidade das fronteiras.

31. MELO NETO. Obra completa, p. 157-158. 
fragilidade, do "pouco", nos limiares da certeza. ${ }^{32}$ A contenção, a firmeza e o ascetismo de Manolete são frutos da consciência de que qualquer gesto indevido pode levar à morte; do mesmo modo, qualquer vazamento de emoção, qualquer palavra indevida podem prejudicar a forma final do poema. As condições adversas impõem ao toureiro, e ao artista, a "precisão" como parâmetro para se alcançar a vitória, a criação, a liberdade. O objeto construído deve comover por sua força concreta.

Em Cabral, Espanha e Pernambuco deslizam como afluentes e formam um terceiro rio. A escritura literária ativa a interpenetração de elementos que partilham dados em comum. Por conhecer, de modo pleno, os dois territórios, abrir-se a eles e deixá-los invadir sua experiência, o poeta permite o surgimento da "diplomacia menor". A partir da desterritorialização de elementos culturais díspares, recompõe os motivos e as influências, retorritorializando as informações em uma nova produção literária. Como o toureiro, o poeta - solitário viajante enfrenta as imagens da morte que o atormentam. Encontra, no espetáculo da arena, o seu sentido maior, a saúde da criação que põe em movimento o gesto de escritura, seu modo particular de manejar a espada.

O conjunto das obras de Cabral e Rosa apresenta um aspecto reflexivo entranhado em suas alegorias e metáforas. Os textos encontram-se dentro dos parâmetros de uma produção artístico-literária questionadora dos lugares discursivos dominantes em certo período histórico. Muitas das personagens dos autores, configuradas como homens comuns, ordinários, conduzem-se pela desregulamentação da máquina ininterrupta da modernidade. A abertura para o "fora" de uma cultura, de uma língua, demonstra a relação da própria literatura com a ideia do exílio, pois essa situação exige do escritor forte propósito de desterritorialização, de deslizamento entre seus repertórios e os novos conteúdos que encontra. 33

O pensamento do "fora" inscrever-se-ia como uma crítica aos postulados platônicos e positivistas do conhecimento. Como crítica à razão, o

32. Escreve o poeta: "Sim, eu vi Manuel Rodríguez,/ Manolete, o mais asceta,/ não só cultivar sua flor/ mas demonstrar aos poetas: // como domar a explosão/ com mão serena e contida,/ sem deixar que se derrame/ a flor que traz escondida,// e como, então, trabalhá-la,/ com mão certa, pouca e extrema:/ sem perfumar sua flor,/ sem poetizar seu poema." MELO NETO. Obra completa, p. 158.

33. Cf. LEVY. A experiência do fora: Blanchot, Foucault e Deleuze, p. 38. 
pensamento surge nos momentos de incerteza e fragilidade diante do novo e do desconhecido. Não estaria no lugar da cópia e do reconhecimento, não buscaria conhecer a verdade, mas produzi-la. A "diplomacia menor" e as "poéticas de fronteiras" demonstram a necessidade do encontro com alguma coisa que force o pensamento a sair de sua interioridade. O acaso dos trajetos, das viagens, dos encontros, o inesperado dos acontecimentos têm forte presença na montagem dessa cartografia voltada para o desconhecido e para a novidade. O acaso dá oportunidade de o próprio pensamento ser posto em dúvida e possibilita o surgimento do devir.

Os escritores-diplomatas podem funcionar como bons exemplos de atuação nas zonas de fronteira das disciplinas e dos saberes, espaços em que a sutileza discursiva pode provocar tanto o desentendimento quanto a abertura para novos "acordos", estes, por sua vez, sempre inconclusos e em processo. Nestes tempos em que o discurso literário aparece enfraquecido devido à hegemonia da tecnociência, do marketing, da razão estratégica e econômica, os estudos literários - em especial a literatura comparada - poderiam contribuir em muito para uma nova modalidade de trabalho com o pensamento, com a imaginação e com a sensibilidade. Esse tipo de abordagem possibilitaria a construção de outros paradigmas para o conceito de saber, vinculando o desenvolvimento tecnológico aos cuidados com a natureza, com o humano, o sub-humano, o pós-humano.

Travels abroad: diplomacy and trans-disciplinarity in João Cabral and Guimarães Rosa

Abstract: This paper aims at reflect on the concept of diplomacy as allegory of the artistic-intellectual work and the transdisciplinar knowledge, taking as example some passages of the life and works of the Brazilian writers João Cabral de Melo Neto and João Guimaräes Rosa. Keywords: Diplomacy, transdisciplinarity and literature. 


$$
\text { Referências }
$$

AGAMBEN, Giorgio. A comunidade que vem. Lisboa: Editorial Presença, 1993. 86 p. ANTELO, Raul. Sentido, paisagem, espaçamento. Margens/Márgenes, Revista de Cultura, Belo Horizonte/ Buenos Aires/ Mar del Plata/ Salvador, n. 5, p. 18-23, jul.dez. 2004.

ARAÚJO, Heloísa Vilhena de. Guimarães Rosa: diplomata. Brasília: Ministério das Relações Exteriores; Fundação Alexandre de Gusmão, 1987.

CASTELLO, José. João Cabral de Melo Neto: o homem sem alma \& diário de tudo. Rio de Janeiro: Bertrand Brasil, 2006. 272 p.

DeleuzE, Gilles. Crítica e clínica. Trad. Peter Pál Pelbart. São Paulo: Ed. 34, 1997. $176 \mathrm{p}$.

DELEUZE, Gilles; PARNET, Claire. Diálogos. Trad. Eloisa Araujo Ribeiro. São Paulo: Ed. Escuta, 1998.

DELEUZE, Gilles. Diferença e repetição. Trad. Luiz Orlandi e Roberto Machado. Rio de Janeiro: Graal, 2006. 437 p.

DOMINGUES, Ivan (Org.). Conbecimento e transdisciplinaridade II: aspectos metodológicos. Belo Horizonte: Editora UFMG, 2005. 413 p.

DERRIDA, Jacques. O animal que logo sou (A seguir). Trad. Fábio Londa. São Paulo: Editora Unesp, 2002. 93 p.

FOUCAULT, Michel. Arqueologia do saber. 7. ed. Trad. Luiz Felipe Baeta. Rio de Janeiro: Forense Universitária, 2007. 236 p.

HISSA, Carlos Eduardo Viana. A mobilidade das fronteiras. Belo Horizonte: Editora UFMG, 2002. 316 p.

LATOUR, Bruno. Políticas da natureza: como fazer ciência na democracia. Trad. Carlos Aurélio Mota de Souza. São Paulo: EDUSC, 2004. 412 p.

LEVY, Tatiana Salem. A experiência do fora: Blanchot, Foucault, Deleuze. Rio de Janeiro: Relume Dumará, 2003. 136 p.

MELO NETO, João Cabral de. Carta a Murilo Rubião. Marselha, 1. XII.958. Arquivo Murilo Rubião. Acervo de escritores mineiros da UFMG.

MELO NETO, João Cabral de. Carta a Murilo Rubião. Marselha, 6. XII. 958. Arquivo Murilo Rubião. Acervo de escritores mineiros da UFMG.

MELO NETO, João Cabral de. Conversas com o poeta João Cabral de Melo Neto. Sibila: revista de poesia e cultura. São Paulo: Sibila edições. Número especial em pdf. Ano 9, n. 13, agosto de 2009. 138 p.

MELO NETO, João Cabral de. Obra completa. Rio de Janeiro: Nova Aguilar, 1999.

MORIN, Edgar. Educação e complexidade: os sete saberes e outros ensaios. In: AlMEIDA, Maria da Conceição; CARVAlHO, Edgard de Assis (Org.). São Paulo: Cortez, 2002. 102 p.

ROSA, João Guimarães. Diário alemão. Fundo Henriqueta Lisboa. Acervo de Escritores Mineiros da UFMG.

ROSA, João Guimarães. Discurso de posse de J.G.R. na ABL. Rascunho. Arquivo IEBUSP. Fundo Guimarães Rosa, caixa 22. doc. 2, 40 p., 10 envelopes. 
ROSA, João Guimarães. Estas estórias. 3. ed. Rio de Janeiro: José Olympio, 1985. 285 p.

ROSA, João Guimarães. Tutaméia: terceiras estórias. Rio de Janeiro: José Olympio Editora, 1967. 194 p.

SANTOS, Boaventura de Sousa. Para um novo senso comum: a ciência, o direito e a política na transição paradigmática. São Paulo: Cortez, 2006. 512 p. v. 4: A gramática do tempo: para uma nova cultura política. 